\title{
Há evidências de desindustrialização no Brasil?
}

ANDRÉ NASSIF*

Are There evidences of deindustrialization in Brazil? This paper aims at analyzing the theoretical concept of deindustrialization, and evaluating if Brazil, following the implementation of economic reforms in the 1990's, has suffered from a "new Dutch disease". Despite the manufacturing sector declining participation in the Brazilian Gross Domestic Product (GDP), the empirical evidence show that the changes in the economy structure since the mid-1980's to the end of 2005 should not be described as deindustrialization. Since there was not evidence of either generalized reallocation of resources towards industries based on natural resources, or a pattern of export specialization in goods technologically based on natural resources or even on labor, one cannot conclude that Brazil was infected by a "new Dutch disease".

Key-words: deindustrialization; Dutch disease; productivity; international specialization; Brazil.

JEL Classification: 012; 014; 024.

\section{INTRODUÇÃO}

O suposto problema da desindustrialização recorrentemente vem à baila nos debates acadêmicos e políticos no Brasil, ainda que sob a roupagem de diferentes concepções. Na segunda metade dos anos 1990, argumentava-se que o processo de liberalização comercial teria provocado uma forte reprimarização da pauta de

\footnotetext{
* Economista da Área de Planejamento do BNDES, e-mail: andrenassif@bndes.gov.br. Júlio Sérgio Gomes de Almeida, Fábio Giambiagi, Paulo Gonzaga M. de Carvalho, Sheila Najberg, Fernando Pimentel Puga, Daniel da Silva Grimaldi e dois pareceristas anônimos da REP fizeram sugestões importantes, a maioria das quais incorporada na versão final. O mérito da elaboração dos dados primários deve ser creditado ao competente estagiário Daniel da Silva Grimaldi. Mário Costa Levorato Jr. prestou enorme colaboração na programação computacional que permitiu converter os códigos da Nomenclatura Brasileira de Mercadorias (NBM) para os da Nomenclatura Comum do Mercosul (NCM). Os argumentos e conclusões são, como de praxe, de responsabilidade do autor. Submetido: Julho 2006; aceito Novembro 2006.
} 
exportações brasileira. ${ }^{1}$ Recentemente, a eventual desindustrialização no País seria manifestada por uma nova forma de "doença holandesa" (Dutch disease). ${ }^{2}$ Para Palma (2005), em vez de um processo desencadeado pela descoberta de recursos naturais (como no caso clássico que afetou a Holanda nos anos 1970) ou mesmo pelo desenvolvimento e boom exportador do setor de serviços, a nova "doença holandesa" que atingiu o Brasil e outros países da América Latina teria sido conseqüência da drástica mudança do velho regime de substituição de importações por outro que, a partir da década de 1990, combinou liberalização comercial e financeira com profundas mudanças institucionais. Nessa versão, as novas políticas econômicas teriam acarretado não apenas perda relativa e precoce de participação da indústria no PIB, como principalmente o retorno a um padrão de especialização internacional baseado em produtos intensivos em recursos naturais. Nas palavras de Palma (2005), essa nova "doença holandesa" teria enquadrado o Brasil no grupo de países com padrão de especialização "ricardiano rico em recursos" (p.19).

Uma interpretação complementar acrescenta que a referida tendência à desindustrialização tem sido reforçada, desde 2004, pela combinação de taxas de câmbio reais excessivamente baixas (ou seja, forte apreciação da moeda brasileira em termos reais) com o expressivo aumento dos preços relativos das principais commodities exportadas pelo país. ${ }^{3}$

\footnotetext{
${ }^{1}$ Ver, por exemplo, Gonçalves (2000, pp.93-95). Em livro recente, essa conclusão foi reiterada pelo mesmo autor [ver Gonçalves (2005, pp.264-267 e 276-279)].

${ }^{2}$ A "doença holandesa" original está relacionada a um fenômeno real ocorrido na Holanda, nos anos 1970, quando a descoberta de grandes fontes de gás natural provocou uma forte realocação dos recursos na economia do país. No médio prazo, no entanto, o boom das vendas externas da commodity levou a uma enorme apreciação real do florim holandês e, por conseguinte, à depressão das exportações industriais do país. Após a ocorrência real do problema na Holanda, a teoria da Dutch disease foi desenvolvida pioneiramente por Corden e Neary (1982). Para esses autores, uma economia padece da doença holandesa quando a rentabilidade de um ou mais setores é fortemente comprimida como decorrência de um boom ocorrido em determinadas indústrias produtoras de bens ou serviços comercializados (traded goods). Jones e Neary (1984, p.25) mostraram também que a retração dos demais setores da economia pode ser ainda mais acentuada, caso o efeito-gasto decorrente do boom aumente desproporcionalmente a rentabilidade dos setores que produzem bens não-comercializados (non-traded goods).

${ }^{3}$ Essa tem sido a interpretação de Bresser Pereira (2005) e Barros (2006), entre outros. Acrescente-se, outrossim, que nesta linha de interpretação o aumento expressivo do preço internacional das principais commodities exportadas pelo Brasil contribuiu para deslanchar as vendas externas recentes e, por conseguinte, para a apreciação cambial, supondo todas as demais variáveis constantes. Nota-se, portanto, que esse raciocínio sugere que a relação de causa e efeito entre taxa de câmbio real e exportações é ambígua: se, por um lado, a apreciação do Real tende, tudo o mais constante, a reduzir as vendas externas, por outro lado, o aumento do preço das commodities contribui para deflagrar um boom exportador no Brasil e este, por sua vez, reforça a tendência de apreciação cambial. No longo prazo, entretanto, o resultado seria pernicioso tanto pelos efeitos micro quanto macroeconômicos: a apreciação do Real reduz a competitividade dos bens industrializados, redireciona a especialização para produtos primários e/ou industrializados intensivos em recursos naturais e potencializa os riscos de crise cambial.
} 
Este artigo tem o duplo objetivo de analisar o conceito de desindustrialização à luz da teoria econômica e de avaliar se, de fato, o Brasil foi atingido pela "nova doença holandesa”. Esta, por sua vez será aqui identificada, de um lado, por uma generalizada realocação de recursos para setores primários ou para indústrias tecnologicamente tradicionais, e, de outro lado, pela mudança do padrão de especialização internacional na direção de produtos primários e/ou industrializados intensivos em recursos naturais. A metodologia utilizada para a análise das evidências empíricas contemplará dois aspectos: a evolução recente da produtividade do trabalho na indústria, porque constitui o cerne da discussão teórica sobre desindustrialização na literatura; e as mudanças ocorridas na estrutura e no padrão de especialização intra-industrial, cujos resultados permitirão avaliar se o Brasil estaria sendo, de fato, acometido pelos sintomas da alegada "nova doença holandesa".

Além da Introdução, o artigo contém mais cinco seções. A Seção 2 analisa o problema da desindustrialização de acordo com a literatura econômica sobre a questão. A Seção 3 investiga o comportamento da produtividade industrial brasileira como ponto de partida preliminar para averiguar a suposta existência de desindustrialização no país. A Seção 4 procura responder, também em caráter provisório, se a experiência brasileira relativa à perda de participação da indústria (em termos de valor adicionado) no PIB se enquadra na tendência geral observada nos países desenvolvidos. A Seção 5 analisa as principais evidências empíricas sobre as mudanças internas na estrutura industrial e no padrão de especialização, com base nas quais poderemos responder, de forma mais precisa, se, de fato, esteve ou está em curso um processo de desindustrialização no país. A Seção 6 apresenta as principais conclusões do trabalho.

\section{O CONCEITO DE DESINDUSTRIALIZAÇÃO NA LITERATURA ECONÔMICA}

Ao contrário do que pode suspeitar o senso comum, a desindustrialização de um país não é necessariamente um fenômeno negativo seja em relação à sustentação do crescimento econômico no longo prazo, seja com respeito ao padrão de bem-estar de sua sociedade. A tendência à desindustrialização como percurso natural do processo de desenvolvimento econômico dos países capitalistas já estava implícita nos estágios formulados por Clark (1957), segundo os quais as mudanças nos níveis de elasticidade-renda da demanda para produtos industrializados (maior do que 1 para países com níveis baixos e médios de renda per capita; e ligeiramente menor do que 1, para países com níveis elevados de renda per capita) explicam os ganhos relativos da participação do setor de serviços na renda e emprego totais, em detrimento da perda relativa do setor industrial. Ou seja, na formulação pioneira de Clark (1957), países de renda muito baixa contam com maior participação relativa dos setores primários no PIB, mas à medida que alcançam 
níveis médios de renda per capita essa participação majoritária é transferida para o setor industrial. Quando alcançam finalmente níveis elevados (e sustentáveis) de renda per capita, a perda de participação do setor industrial no produto agregado e, principalmente, no emprego total é transferida para o setor de serviços.

$\mathrm{Na}$ consolidação do conceito elaborada por Rowthorn e Wells (1987), a desindustrialização é definida como um fenômeno caracterizado principalmente pela retração relativamente expressiva do emprego no setor manufatureiro vis-à-vis os demais setores, notadamente o de serviços. No entanto, sem negar o papel da mudança dos níveis de elasticidade-renda da demanda para produtos manufaturados no curso do desenvolvimento econômico, os autores adicionam uma hipótese mais importante para explicar o fenômeno da desindustrialização: em economias avançadas, em que pese a taxa de crescimento do valor adicionado pelos setores manufatureiro e de serviços ser mais ou menos a mesma, os níveis de incremento da produtividade do trabalho do primeiro tendem a ser superiores aos do último.

Em trabalho mais recente, Rowthorn e Ramaswany (1999) reafirmam, a la Clark (1957), que "a desindustrialização em economias avançadas não é necessariamente um fenômeno indesejável, mas essencialmente uma conseqüência natural do dinamismo exibido por esses países" (p. 19). No entanto, retomam a hipótese dos diferenciais de produtividade entre os setores industrial e de serviços em economias maduras para concluir que, na prática, a desindustrialização se manifesta como um fenômeno em que a perda da importância da indústria vis-àvis o setor de serviços tende a ser mais expressiva em termos da participação relativa no emprego total que na oferta total. O principal argumento é que o ritmo mais intenso de crescimento da produtividade do setor manufatureiro frente aos demais setores em economias avançadas provoca queda acentuada dos preços relativos dos bens industrializados e, por conseguinte, um forte estímulo à demanda desses produtos, mais do que compensando os níveis de elasticidade-renda marginalmente inferiores a 1 , observados em países de alta renda per capita. $\mathrm{Pa}$ ralelamente, o ritmo intenso da produtividade do setor manufatureiro explica a queda relativa do emprego gerado nesse setor, em virtude da introdução de técnicas poupadoras de mão-de-obra. Nesse caso, a desindustrialização é paradoxalmente um fenômeno tecnológico, já que a indústria (ainda) constitui a principal fonte de progresso técnico.

Rowthorn e Ramaswamy (1999) procuram testar empiricamente essas hipóteses para uma amostra de 18 países industrializados durante o período 1963-1994 (variáveis em valor expresso a preços de 1990). Suas principais conclusões são:

1. a variável explicativa de mudança dos preços relativos é a taxa de variação da produtividade do trabalho;

2. existe uma forte correlação entre a participação da indústria no PIB e o nível de renda per capita, o que sugere que a primeira tende a cair quando a última alcança um determinado nível considerado elevado; 
3. O nível de renda per capita considerado como de turning-point, isto é, a partir do qual as forças da desindustrialização começam a atuar é de cerca de US\$8.300,00 (a preços de paridade internacional de poder de compra). ${ }^{4}$

4. a participação de produtos manufaturados no PIB tende a ser impulsionada por elevadas taxas de incremento da formação bruta de capital fixo;

5. há fortes evidências de aumento expressivo da participação relativa do emprego manufatureiro no emprego total nos estágios iniciais e intermediários de desenvolvimento e de queda dessa participação a partir de níveis elevados de renda per capita;

6. as evidências sugerem que a concorrência com importados provenientes dos países em desenvolvimento (em geral intensivos em trabalho e/ou recursos naturais) exercem um efeito marginal na queda da participação do emprego manufatureiro. Em última instância, seu principal impacto é fomentar a produtividade do setor manufatureiro dos países avançados, provocando uma maior especialização em produtos intensivos em capital e/ou de alta tecnologia, em geral poupadores de mão-de-obra.

A literatura existente não é conclusiva em relação ao tema da desindustrialização no Brasil. Feijó e Carvalho (2005) não detectam evidências de retração intempestiva da indústria brasileira. Nakahodo e Jank (2006) contestam "a idéia de que haveria um processo de desindustrialização em curso" no Brasil (p. 19). Para Palma (2005), ao contrário, e conforme já mencionado, há "um processo de desindustrialização prematura atualmente em curso no Cone Sul da América Latina e no Brasil". Na seção seguinte, procuraremos utilizar as hipóteses teóricas resumidas anteriormente e as evidências empíricas sobre o comportamento da produtividade do trabalho na indústria de transformação brasileira para avaliar, em caráter preliminar, se o Brasil já passou ou corre o risco de passar por um processo de desindustrialização.

\section{A PRODUTIVIDADE DA INDÚSTRIA EM PERSPECTIVA DE LONGO PRAZO}

A análise da evolução da produtividade do trabalho na indústria brasileira em perspectiva de longo prazo é um bom ponto de partida porque proporciona

\footnotetext{
${ }^{4} \mathrm{O}$ curioso é que em trabalho anterior, Rowthorn (1994), para uma amostra representativa de 70 países para 1990, indicava que essa renda per capita era de US $\$ 12.000$ (a preços de paridade internacional do poder de compra de 1991). Como mostra Palma (2005, p.8), "desde o início dos anos 1980, tem havido uma redução drástica da renda per capita considerada como necessária (ou seja, de turning point) para deflagrar o processo de desindustrialização e dar início ao declínio do emprego industrial: de US\$20.645 em 1980 para US\$9.805 em 1990, e US\$8.691 em 1998" (todas as cifras expressas em paridade internacional do poder de compra).
} 
os elementos iniciais para responder a principal questão do nosso trabalho: faz sentido falar de desindustrialização no Brasil?

Iremos avaliar o comportamento da produtividade no Brasil por meio de diferentes metodologias e fontes de dados. Com efeito, a produtividade do trabalho costuma ser calculada ora pela razão entre produção física e pessoal ocupado (ou alternativamente, entre produção física e horas pagas), ora pelo quociente entre o valor adicionado e o pessoal ocupado. Cabe ressaltar, no entanto, que, com respeito à primeira metodologia, o valor do numerador (a produção física) é extraído dos índices de quantum utilizados pelo IBGE como proxy para o cálculo do valor adicionado industrial e dos indicadores concernentes ao PIB trimestral. Trata-se, portanto, de uma medida provisória para o cálculo do PIB, cujo valor definitivo só vem a ser divulgado depois de apurados os valores adicionados setoriais pelas Contas Nacionais.

Como mostrou Bruno (1978), em seu artigo clássico sobre o tema, a medida mais adequada de estimação da produtividade do trabalho é, de fato, a razão entre o valor agregado e o pessoal ocupado. A propósito, Bonelli e Fonseca (1998) defendem o uso dessa metodologia, ao reconhecerem que "se os coeficientes técnicos mudarem com o tempo, a medida de produção (os índices de "produção física" real) normalmente utilizada como proxy do produto gerado (isto é, o valor agregado, ou VA) irá gerar resultados viesados".

Apesar disso, justamente por ser o uso da primeira metodologia muito disseminado nos meios acadêmicos e empresariais, calculamos inicialmente o comportamento da produtividade do trabalho pela razão entre a produção física e o pessoal ocupado no setor manufatureiro no período 1984-2005 (média de 12 meses a partir de outubro de cada ano). ${ }^{5}$ Os resultados encontram-se no Gráfico 1.

O Gráfico 1 permite delimitar o comportamento da produtividade do trabalho na indústria brasileira em dois grandes períodos: forte retração na segunda metade da década de 1980; e expressiva recuperação a partir do início da década de 1990. Em linhas gerais, os dados confirmam as evidências já apontadas em diversos trabalhos sobre o tema já publicados no Brasil: na segunda metade da década de 1980, a retração da produtividade é explicada por um aumento do emprego mais que proporcional ao incremento da produção física (em termos tendenciais); a partir da década seguinte, por seu turno, os elevados ganhos de produtividade da indústria são explicados principalmente pelos índices crescentes de expansão da produção física, os quais foram acompanhados, no entanto, ora por um ritmo mais

\footnotetext{
${ }^{5}$ É verdade que a metodologia mais apropriada para o cálculo da produtividade foi objeto de intenso debate no Brasil na primeira metade dos anos 1990. Além disso, é preciso ponderar que a escolha do método de apuração desse indicador por meio da razão produção física/horas trabalhadas (ou produção física/pessoal ocupado) é justificada pela escassez momentânea (ou, às vezes, lentidão na divulgação) de informações estatísticas no Brasil. Só para lembrar, a indispensável Pesquisa Industrial Anual não foi efetuada no ano de 1991, em virtude das restrições de recursos financeiros impostas pelo Governo Collor.
} 
lento de aumento, ora por forte retração do emprego industrial. ${ }^{6}$ No entanto, o Gráfico 1 mostra claramente que, entre 1998 e 2003, o ritmo de crescimento da produtividade foi bem mais lento que o registrado no período 1990-1997.

Gráfico 1: Produtividade do trabalho (PF/PO), produção física (PF) e pessoal ocupado na indústria de transformação (1984-2005) - Índices acumulados (1991=100)

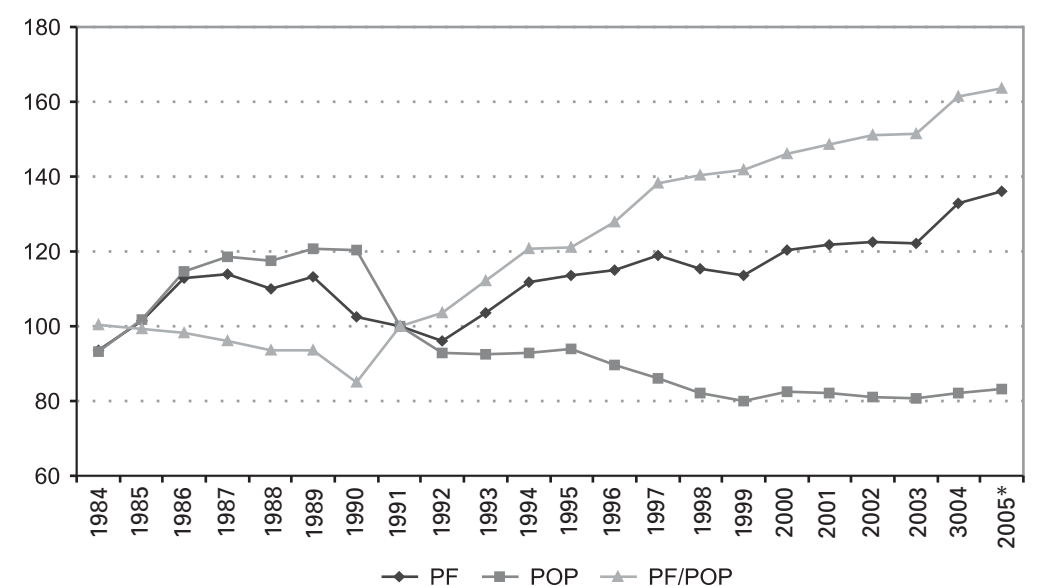

* Valores médios no período de 12 meses até outubro de 2005 (Nov/04 a Out/0 Fonte: IBGE, Pesquisa Industrial Mensal

Diversos estudos empíricos procuraram explicar as fontes de crescimento da produtividade industrial brasileira na década de 1990. As análises indicam que a introdução de novas técnicas de produção e o acesso a bens de capital e insumos importados a preços mais próximos dos internacionais após a liberalização comercial também levaram a um forte enxugamento de mão-de-obra no setor industrial brasileiro. ${ }^{7}$

$\mathrm{Na}$ segunda metade da década de 1980, a produtividade do trabalho na indústria brasileira apresentou quase sistematicamente taxas de variação negativas. Após 1991, entretanto, esse quadro se reverte e em todos os anos o setor manufatureiro mostrou incrementos percentuais na produtividade do trabalho. Já o comportamento da produção física e, principalmente do emprego industrial no período, foi bem mais volátil. Em média, prevaleceu uma queda no emprego industrial, a partir dos anos 1990.

\footnotetext{
${ }^{6}$ Ver, entre outros, Salm, Sabóia e Carvalho (1997), Bonelli e Fonseca (1998), Hay (2001), Muendler (2004) e Nassif (2005).

${ }^{7}$ Ver Carvalho (2000 , cap.V), que resume o debate sobre os impactos do aumento da produtividade sobre o emprego industrial na década de 1990 e corrobora essa conclusão. Bonelli e Fonseca (1998) mostram que o aumento acumulado de $43 \%$ na produtividade do trabalho na indústria foi acompanhado por cerca de $16 \%$ de retração do emprego neste mesmo setor entre 1992 e 1996 . Os autores concluem que "as variações de emprego e de produtividade têm uma correlação relativamente pequena entre si" e estimam que "para cada $1 \%$ de aumento da produtividade ocorreu uma redução média de cerca de $0,24 \%$ do nível de emprego" (pp. 33-34).
} 
É interessante checar esses resultados com a estimação da evolução da produtividade do trabalho com base nos dados da Pesquisa Industrial Anual (PIA), do IBGE, cujas informações são obtidas diretamente junto às empresas brasileiras. Nesse caso, a produtividade do trabalho foi calculada com base na razão entre o valor agregado industrial e o pessoal ocupado, conceito amplamente difundido pela teoria econômica e, como já antecipado, mais apropriado para a estimação do referido indicador e menos sujeito a resultados viesados. Os indicadores ficaram restritos ao período 1996-2004, em virtude das mudanças introduzidas na metodologia da PIA em 1995.

O Gráfico 2 mostra o comportamento da produtividade do trabalho (expresso em números-índice na parte superior, e em taxas anuais de crescimento, na parte inferior). Os resultados obtidos mostram que, diferentemente da medida de produção física/pessoal ocupado, houve tendência de retração dos índices de produtividade do trabalho a partir da segunda metade da década de 1990, sobretudo no período posterior a 1999 , quando o indicador passou a apresentar taxas negativas de variação. ${ }^{8}$ No período 1996 -2004, a variação média anual da produtividade do trabalho da indústria de transformação brasileira foi da ordem de $-2,6 \%$. Um sinal de reversão dessa tendência só ocorre em 2004 , quando a produtividade do trabalho registrou acréscimo de $1 \%$.

Gráfico 2: Valor agregado (VA), pessoal ocupado e produtividade do trabalho na indústria de transformação brasileira (1996-2004): número índice (1996 = 100) e taxa de variação anual (\%)
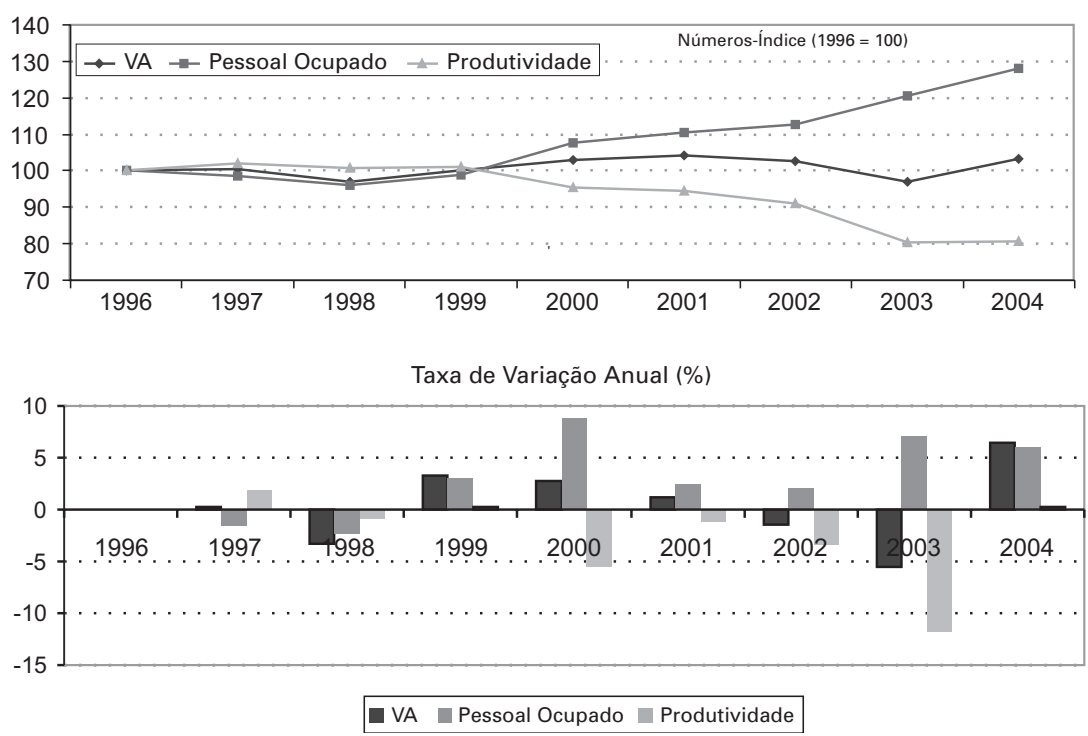

Obs: Para o cálculo da produtividade do trabalho, o valor agregado industrial foi deflacionado com base no IPA-DI, a preços de junho de 1996. Fonte: IBGE, Pesquisa Industrial Anual. Elaboração própria.

\footnotetext{
${ }^{8}$ Note que a taxa de variação da produtividade do trabalho na indústria de transformação em 1999 foi de apenas $1 \%$, como mostra a parte inferior do Gráfico 2.
} 
A fim de checar se esse último resultado não teria sido distorcido pelos índices de preços utilizados como deflatores para o cálculo do valor adicionado a preços de 1996, isolamos o setor de bens de capital e calculamos sua respectiva produtividade média relativamente à indústria de transformação como um todo. ${ }^{910}$ Se a taxa de variação da produtividade do trabalho da indústria de bens de capital for inferior à da indústria de transformação como um todo, a taxa de variação da produtividade média relativa daquela será negativa, e vice-versa. No período 1996-2004, a indústria de bens de capital sofreu uma retração média anual da produtividade do trabalho da ordem de $-2,9 \%$ e sua produtividade média relativa teve queda de $-0,1 \%$ a.a.. Esses valores sugerem que a retração da produtividade da indústria de transformação foi ligeiramente menor. De fato, essa expectativa é consistente com nossas estimativas anteriores, de retração da produtividade do trabalho da indústria de transformação da ordem de $-2,6 \%$ a.a. em igual período. Com isso, pode-se concluir que os deflatores não distorceram os resultados estimados da produtividade do trabalho que aparecem no Gráfico 2.

Além disso, o comportamento da produtividade descrito no Gráfico 2 foi muito similar aos resultados estimados por trabalhos recentes que utilizaram a mesma metodologia (valor adicionado por trabalhador). Com efeito, utilizando os dados das Contas Nacionais, IEDI (2005, p. 5) mostra uma queda acumulada de $-3,1 \%$ na produtividade industrial no período 1998-2003. Suas estimativas sugerem que a reversão da tendência de crescimento da produtividade do trabalho na indústria de transformação na década terá ocorrido entre 1998 e 1999, já que no período anterior os índices acumulados foram positivos (1990-1994: 111,7\%; 1994-1998: $12,1 \%)$. Tal tendência vai também na direção das estimativas de Feijó, Carvalho e Almeida (2005), que, com base em metodologia similar, chegaram aos seguintes resultados em termos de taxas de incremento anuais da produtividade na indústria de transformação: 1991-1994: 5\%; 1995-1998: 3,2\%; e 1999-2003: -0,5\%.

\footnotetext{
${ }^{9} \mathrm{O}$ setor de bens de capital que isolamos, a partir de diversos códigos da Classificação Nacional de Atividades Econômicas (CNAE) do IBGE, não se restringiu à indústria de máquinas e equipamentos convencional (código 29 da CNAE, utilizado na Pesquisa Industrial Anual - PIA). Criamos uma tipologia para a indústria de bens de capital cuja classificação se baseou na relação fornecedor-usuário e que compreendeu os seguintes setores: máquinas e equipamentos tipicamente industriais, máquinas e equipamentos de energia elétrica, máquinas e equipamentos de telecomunicações, máquinas e equipamentos eletrônicos e não-eletrônicos, máquinas e equipamentos médico-hospitalares, máquinas e equipamentos agrícolas e máquinas e equipamentos de transporte. Estes setores, em conjunto, representavam, em 2004, cerca de $17 \%$ do total do valor adicionado da indústria de transformação brasileira. É conveniente acrescentar que a escolha do setor de bens de capital, em detrimento de outros setores, decorreu apenas da coincidência de o autor estar, na ocasião, desenvolvendo trabalho sobre aquela indústria e, por isso, já dispor dos resultados mencionados.

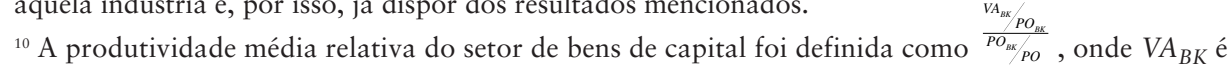
o valor adicionado a preços correntes do setor de bens de capital, VA é o valor adicionado a preços correntes da indústria de transformação como um todo, $P O_{B K}$ é o pessoal ocupado no setor de bens de capital e $P O$ é o total de trabalhadores empregados na indústria como um todo. Com isso, usamos uma medida de produtividade que prescinde do uso de deflatores de preços.
} 
Gráfico 3: Formação Bruta de Capital Fixo (\% do PIB)

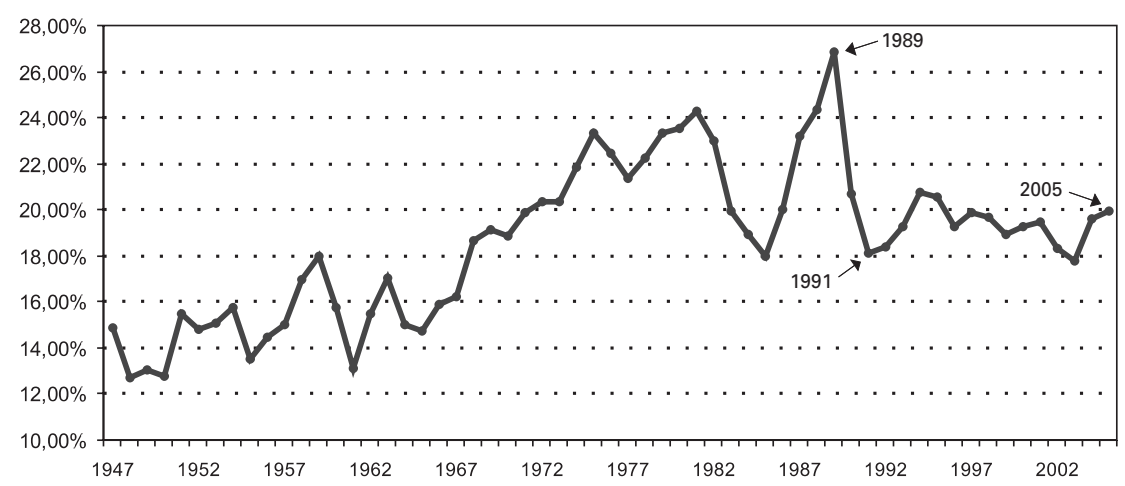

Fonte: IPEADATA

Finalmente, cabe destacar que a recuperação dos índices positivos de produtividade no início da década de 1990 foi acompanhada, no entanto, por uma retração da taxa de investimento. ${ }^{11} \mathrm{O}$ Gráfico 3 mostra que a taxa de investimento bruto da economia caiu significativamente no início dos anos 1990 em relação às taxas médias anuais da década anterior. É preciso ressaltar ainda que, ao longo dos anos 1990, as taxas de investimento bruto no Brasil continuaram, em média, relativamente baixas, e não retornaram aos níveis médios prevalecentes na década de 1980. Tais resultados, combinados com um quadro em que as taxas de variação positivas da produtividade observadas na primeira metade dos anos 1990 não se sustentaram após a segunda metade desta mesma década, podem ter contribuído para a perda de participação do setor industrial no PIB brasileiro. Essa conjectura será investigada na próxima seção.

\section{AS MUDANÇAS NA ESTRUTURA PRODUTIVA BRASILEIRA}

Embora o início dos anos 1930 seja normalmente delimitado como o limiar do processo de industrialização no Brasil sob a égide do modelo de substituição

\footnotetext{
${ }^{11}$ Existem evidências empíricas relativamente robustas para explicar as principais fontes de crescimento da produtividade na década de 1990. A maior parte dos estudos conclui que o aumento da eficiência do trabalho no Brasil nesse período foi proporcionado pela absorção de novas técnicas produtivas - haja vista os menores custos relacionados à importação de máquinas e equipamentos, após a liberalização comercial —, mas principalmente pela forte retração do emprego na indústria de transformação. Ver, entre outros, Carvalho (2000), Hay (2001) e Muendler (2004). Em regressão econométrica que permite decompor as fontes de crescimento da produtividade do trabalho na indústria de transformação entre 1988 e 1998, Nassif (2005) concluiu que, dos ganhos totais de eficiência estimados para o período, cerca de $55 \%$ decorreram do enxugamento de mão-de-obra e $40 \%$, da absorção de novas tecnologias. Para mais detalhes, ver Nassif (2005).
} 
de importações, é a partir da década de 1950 que a evolução do setor industrial adquire maior impulso com a implantação da indústria pesada. No final dos anos 1970, por seu turno, com a modernização de diversos segmentos industriais já existentes (sobretudo bens de capital e siderurgia) e a consecução de investimentos em ramos pesados produtores de bens intermediários (petróleo e petroquímica, papel e celulose, entre outros) e em infra-estrutura energética (hidrelétricas, Programa Nuclear, Programa do Álcool), a matriz industrial brasileira já se encontrava praticamente consolidada. Assim, é razoável esperar que tenham ocorrido profundas mudanças na estrutura produtiva brasileira ao longo desse período.

O Gráfico 4 confirma tais expectativas. Ao longo do processo de constituição e consolidação da indústria brasileira (grosso modo, entre 1950 e 1980), a mudança da estrutura produtiva reproduz, em linhas gerais, o padrão de comportamento previsto pela literatura teórica e pelas experiências de desenvolvimento observadas na maioria dos países: perda acentuada de participação da agropecuária em favor de um ganho expressivo de participação da indústria de transformação no PIB. Com isso, em 1980 a estrutura produtiva brasileira tinha características bastante distintas da registrada em 1950: a agropecuária teve sua participação no PIB reduzida de $24 \%$ para aproximadamente $10 \%$, ao passo que a indústria aumentou sua participação de $18 \%$ para $31 \% .^{12}$

Gráfico 4: A estrutura produtiva brasileira (1947-2004):

participação dos setores da atividade econômica no PIB (em \%)

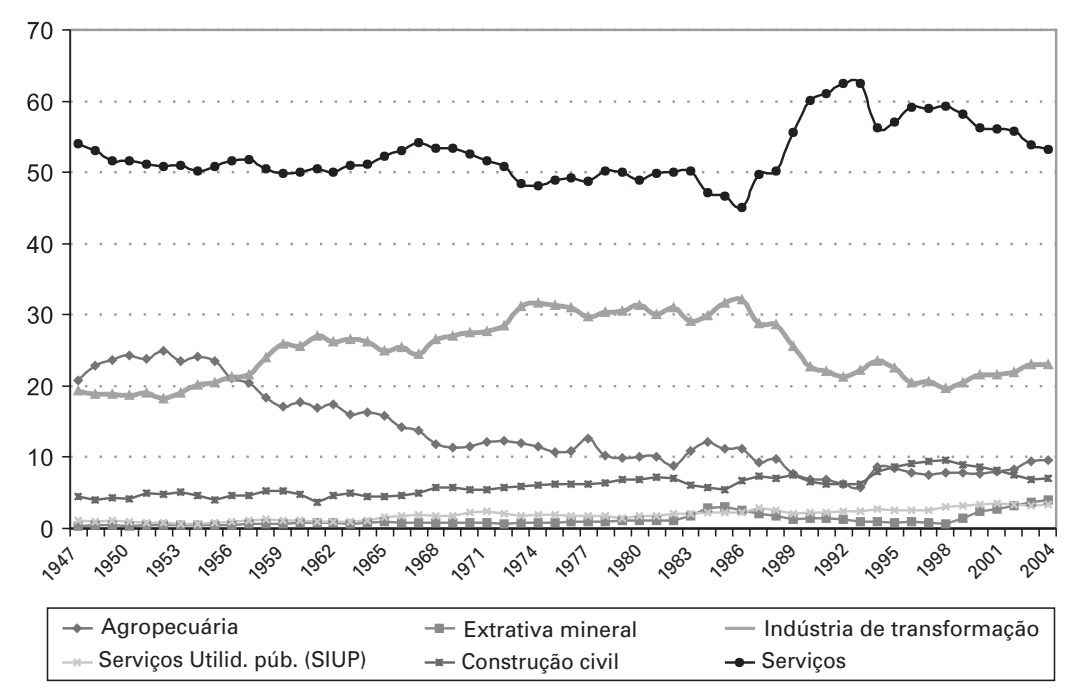

Fonte: IBGE

\footnotetext{
${ }^{12}$ Bonelli (2005) calcula as participações percentuais de cada setor no PIB para o período 1900-2000, a preços constantes de 1949, e compara com os resultados a preços correntes. Os resultados seguem as mesmas tendências ilustradas no Gráfico 4.
} 
Na segunda metade dos anos 1980, no entanto, observa-se uma significativa mudança na evolução da estrutura produtiva brasileira. Com efeito, após preservar, de forma relativamente estável, uma participação média anual de 30,7\% no PIB entre 1973 e 1985 e de alcançar a participação recorde de 32\% no PIB em 1986, a indústria de transformação começa a perder, de forma sustentada, significativa participação relativa no fluxo global de riqueza do país. No início do processo de liberalização comercial, em 1990, essa participação já havia sido reduzida para $22,7 \%$.

A queda na participação da indústria de transformação foi acompanhada por uma elevação na participação do setor de serviços no PIB brasileiro. ${ }^{13}$ Cabe ressaltar, de todo modo, que, pelo menos enquanto tendência, a retração expressiva da participação da indústria de transformação no PIB foi um fenômeno basicamente restrito à segunda metade dos anos 1980. De fato, ao menos como tendência, essa queda contínua foi interrompida ao longo da década de 1990, quando o peso do setor no PIB se manteve em torno de uma média anual de $22 \%$ (contra $29,8 \%$ na década anterior, após ter alcançado 32,1\% em 1986). ${ }^{14}{ }^{15}$ Nos últimos anos, houve um ligeiro aumento dessa participação, chegando a $23 \%$ em 2004. ${ }^{16}$

Até aqui, temos indícios para suspeitar que as mudanças ocorridas na segunda metade da década de 1980 não têm a ver com desindustrialização na concepção do termo consagrada pela literatura econômica, e tampouco com desindustrialização precoce em relação ao estágio de desenvolvimento econômico do País. ${ }^{17}$ Afinal, a queda na participação da indústria no PIB antecedeu ao processo de re-

\footnotetext{
${ }^{13}$ Nas Contas Nacionais, o setor de Serviços é composto pelos seguintes itens: Comércio, Transporte, Comunicações, Instituições Financeiras, Outros Serviços, Aluguéis e Administração Pública.

${ }^{14}$ Cabe ressaltar que a participação da indústria de transformação no PIB chegou a recuperar-se em 1994, quando alcançou a cifra de 23,5\%, mas novamente retraiu-se, atingindo, em 1998, sua menor cifra (de apenas 19,8\%) desde o início dos anos 1970. De qualquer forma, isso não muda as evidências de que, em termos de médias anuais, a participação do setor industrial no PIB brasileiro ficou em torno de $22 \%$ no período 1990-2004.

${ }^{15}$ Pesquisas empíricas disponíveis [ver, por exemplo, Moreira e Correa (1996)] concluem que, em vez de provocar uma profunda alteração na estrutura setorial do PIB brasileiro, o principal impacto das reformas estruturais (notadamente a liberalização comercial) foi no sentido de produzir modificações na estrutura interna do setor industrial doméstico, estas, por sua vez, consubstanciadas no incremento do valor adicionado relativo de setores que utilizam intensivamente os fatores abundantes existentes no Brasil (recursos naturais e trabalho) e, em contrapartida, na redução relativa de alguns setores intensivos em capital e de tecnologia de fronteira. Essa questão será analisada na próxima seção.

${ }^{16}$ Existem interpretações distintas com relação ao comportamento do peso relativo da indústria no PIB. IEDI (2005), por exemplo, conclui que a modesta taxa de expansão da indústria manufatureira nos anos 1990 não permitiu que ela liderasse (pelo menos até 1998) o crescimento do PIB brasileiro e "esta precoce renúncia (à liderança) pode ser considerada uma forma de desindustrialização" (p.10).

${ }^{17}$ Basta lembrar que o Brasil, àquela altura, estava bastante aquém da renda per capita de cerca de US\$20.000, considerada como de turning-point para deflagrar um processo de desindustrialização segundo as evidências empíricas já mencionadas.
} 
formas econômicas estruturais da década de 1990 (liberalização comercial, privatizações, liberalização financeira externa, dentre outras).

De fato, a perda de participação relativa da indústria de transformação no PIB brasileiro nesse período, longe de ter sido movida pelos fatores microeconômicos internos ou externos que costumam explicar a desindustrialização em países avançados (como o aumento mais rápido da produtividade do setor manufatureiro relativamente ao setor de serviços, uma vez alcançado o turning-point de renda per capita ou a pressão competitiva com produtos importados), parece ter decorrido de um forte decréscimo da produtividade industrial nos anos 1980, em um quadro de estagnação econômica e conjuntura de alta inflação. Na primeira metade da década seguinte, as taxas de crescimento médias anuais positivas observadas na produtividade do trabalho não se sustentaram após 1999, e, aliado ao forte declínio do investimento bruto da economia, a indústria de transformação não foi capaz de recuperar os níveis elevados de participação no PIB que prevaleceram até meados da década anterior.

Assim sendo, se até aqui não identificamos a emergência da desindustrialização no Brasil tal como normalmente ocorre nos países desenvolvidos - e conforme o termo consagrado pela literatura econômica -, na seção seguinte procuraremos detectar as mudanças observadas na estrutura interna da indústria e no padrão de especialização internacional, para avaliar, finalmente, se aquele fenômeno se manifestou no Brasil sob a forma de uma "nova doença holandesa".

\section{AS MUDANÇAS NA ESTRUTURA INTERNA DA INDÚSTRIA E NO PADRÃO DE ESPECIALIZAÇÃO DA ECONOMIA BRASILEIRA: UMA "NOVA DOENÇA HOLANDESA"?}

De acordo com a conclusão de Palma (2005), o Brasil teria sido contagiado pela "nova doença holandesa", porque a combinação de medidas liberalizantes com políticas macroeconômicas que, em geral, deixam a taxa de câmbio real baixa (ou seja, a moeda brasileira fortemente apreciada em relação ao dólar em termos reais) modificou o padrão de especialização internacional, com maior concentração na pauta de exportações de produtos primários e industrializados intensivos em recursos naturais. ${ }^{18}$ Nesta seção procuraremos checar se e até que ponto essa conclusão é consistente com as evidências empíricas disponíveis a respeito das modificações ocorridas na estrutura industrial brasileira e no padrão de especialização internacional.

\footnotetext{
${ }^{18}$ Como já mencionado, a conclusão de Bresser-Pereira (2005) e Barros (2006) é similar à de Palma (2005), com a exceção de que aqueles autores não atribuem à causa da "desindustrialização" por doença holandesa o conjunto de medidas liberalizantes introduzidas ao longo da década de 1990, mas apenas à apreciação do Real.
} 
Tendo em conta que, desde 1990 até 2004, a indústria brasileira (incluindo a extrativa mineral) conservou uma participação média anual de $23,5 \%$ no PIB, as tabelas seguintes procuram elucidar as eventuais mudanças ocorridas em sua estrutura interna e no padrão de especialização internacional. Os diversos segmentos da indústria aparecem classificados por tipo de tecnologia, de acordo com a tipologia sugerida pela OECD (1987), também utilizada por Lall (2000a), e inspirada na taxonomia clássica proposta por Pavitt (1984). ${ }^{19}$ Essa taxonomia associa cada tipo de tecnologia ao fator preponderante que molda o posicionamento competitivo das empresas e setores no curto e no longo prazo. Nas indústrias com tecnologias intensivas em recursos naturais, o principal fator competitivo é o acesso a recursos naturais abundantes existentes no país; nas intensivas em trabalho, o mais relevante é a disponibilidade de mão de obra de baixa e média qualificação com custos relativos reduzidos em relação a outros países; nos setores intensivos em escala, as plantas produtivas são caracterizadas por indivisibilidades tecnológicas e, por isso mesmo, o principal fator de competitividade é a possibilidade de explorar ganhos por produzir em grande escala; nos setores com tecnologia diferenciada, os bens são fabricados para atender a diferentes padrões de demanda; e nas indústrias science-based, o principal fator competitivo é a rápida aplicação da pesquisa científica às tecnologias industriais (Lall, 2000a, p.34).

Grosso modo, os setores com tecnologias baseadas em recursos naturais e intensivas em trabalho têm maior capacidade para gerar empregos diretos. Os setores com tecnologias intensivas em escala, diferenciada e baseadas em ciência, por seu turno, por possuírem, salvo exceções, maior intensidade na relação capital/trabalho (notadamente os intensivos em escala) e maior sofisticação tecnológica em seus processos produtivos, têm, por isso mesmo, maior capacidade não somente para promover efeitos de encadeamento para frente e para trás - e, portanto, maiores efeitos multiplicadores de renda e emprego - como também para produzir e difundir inovações para o restante da economia.

Como mostram diversas pesquisas empíricas recentes, os setores com tecnologia diferenciada e baseada em ciência têm atuado, particularmente, como os principais responsáveis pela maximização dos ganhos de produtividade nas economias e pela sustentação do crescimento econômico no longo prazo. ${ }^{20}$ Van Ark, Inklaar e McGuckin (2003) lembram que "vários estudos empíricos sugerem que as menores taxas de investimento nos setores de tecnologia da informação e co-

\footnotetext{
${ }^{19}$ Para mais detalhes, ver OECD (1987) e Lall (2000a).

${ }^{20}$ Ver, entre outros, McKinsey Global Institute (2001), Jorgenson, Ho e Stiroh (2002) e Brynjolfsson e Hitt (2003), que atribuem às taxas mais elevadas de investimento nos setores de tecnologia da informação e de comunicação as elevadas taxas de crescimento da produtividade e a sustentação do crescimento econômico nos Estados Unidos desde meados da década de 1990. Numa perspectiva de longo prazo, Reinert (1999) comenta que "um elemento comum em todas as estratégias bem-sucedidas de catching-up, nos países atualmente industrializados, foi a convicção de que a adesão incondicional a práticas de livre-comércio não ocorreu até que essa nações tenham criado vantagens comparativas nas atividades econômicas "corretas" (que são atividades baseadas em capacitações e conhecimento, não em recursos naturais)”.
} 
municação figuram como o principal fator explicativo para o menor incremento dos índices de produtividade nos países europeus em relação aos Estados Unidos no período recente".

Assim sendo, para que a hipótese de desindustrialização manifestada pelos diversos focos da "nova doença holandesa" seja válida para o caso brasileiro, uma parte expressiva dos segmentos que constituem as indústrias com tecnologia intensiva em escala, diferenciada e baseada em ciência deverá mostrar, simultaneamente, perda de participação no valor adicionado e nas exportações totais da indústria.

A tabela 1 informa sobre as mudanças ocorridas na importância relativa de cada setor no total do valor adicionado industrial.

O diagnóstico de Palma (2005) de que teria havido desindustrialização merece cautela em virtude das seguintes evidências apontadas pela tabela $1:$ i) o segmento de refino de petróleo explica, isoladamente, a quase totalidade do aumento da participação do grupo no valor adicionado industrial total; ou seja, o avanço deste segmento na estrutura industrial brasileira, longe de apontar para um processo de desindustrialização, apenas reflete o progresso tecnológico de um ramo produtivo no Brasil que, embora aproveite a (agora) abundante disponibilidade de matéria-prima básica como sua principal âncora de competitividade, mobiliza elevado montante de capital por unidade de produto gerado; ii) a participação do grupo com tecnologias intensivas em trabalho no total do valor adicionado industrial diminuiu em igual período, o que contraria os novos focos de desindustrialização por doença holandesa, em que seria de esperar maior alocação de recursos para os fatores abundantes no país (trabalho e recursos naturais, em detrimento de capital e tecnologia); e iii) os setores industriais com tecnologias intensivas em escala e baseadas em ciência mantiveram em 2004 praticamente a mesma participação no valor adicionado total que detinham em 1996.

A tabela 2 mostra as mudanças ocorridas no padrão de especialização internacional da indústria brasileira, segundo a mesma tipologia anterior, mas cobrindo o período posterior à deflagração das reformas estruturais no Brasil (1989-2005).

Grosso modo, é possível subdividir o comportamento das exportações industriais como um todo em dois sub-períodos: o primeiro, de estagnação, referente ao período 1989-1999, em que as taxas de crescimento das vendas externas de bens industrializados brasileiros, por terem sido afetadas, principalmente, pela tendência de apreciação cambial (notadamente entre 1994 e 1998), foram extremamente baixas e inferiores às taxas de incremento das exportações mundiais; ${ }^{21}$ o segundo, de boom, ocorrido no período pós-1999, em que as taxas mé-

\footnotetext{
${ }^{21}$ Estimativas da Funcex, com base na metodologia proposta por Guimarães (1995), mostram que a tendência de apreciação do Real, embora se tenha agravado no período 1994-1998, remonta ao início dos anos 1990. Tomando agosto de 1994 como ano-base, os índices médios da taxa de câmbio real R\$/US\$ foram os seguintes para os anos selecionados: 1988: 135,3; 1994: 104,9; 1998: 95,4. Mais adiante, veremos que a tendência de apreciação da moeda brasileira em relação ao Dólar ocorreu também em termos reais efetivos, ou seja, uma vez ponderadas as taxas de câmbio pela participação dos principais parceiros comerciais na pauta de exportações brasileira.
} 
Tabela 1: Composição do valor adicionado na indústria brasileira por tipo de tecnologia no período 1996-2004 (em \%)

Valor adicionado setorial (participação em \%)

\begin{tabular}{|c|c|c|c|c|c|c|c|c|c|}
\hline Setores industriais com tecnologia & 1996 & 1997 & 1998 & 1999 & 2000 & 2001 & 2002 & 2003 & 2004 \\
\hline Baseada em recursos naturais & 32,70 & 32,09 & 33,36 & 36,79 & 38,32 & 39,15 & 40,05 & 42,474 & 40,10 \\
\hline Extração de carvão mineral & 0,07 & 0,08 & 0,08 & 0,07 & 0,08 & 0,06 & 0,06 & 0,06 & 0,07 \\
\hline Extração de Petróleo, gás e serviços relacionados & 0,03 & 0,03 & 0,05 & 0,04 & 0,05 & 0,09 & 0,25 & 0,32 & 0,34 \\
\hline Extração de minerais metálicos & 1,46 & 1,55 & 1,87 & 2,28 & 2,07 & 2,21 & 2,28 & 2,22 & 2,52 \\
\hline Extração de minerais não-metálicos & 0,68 & 0,62 & 0,65 & 0,62 & 0,58 & 0,58 & 0,56 & 0,56 & 0,52 \\
\hline Alimentos e bebidas & 17,22 & 17,53 & 17,69 & 16,45 & 14,05 & 16,09 & 16,26 & 16,201 & 15,22 \\
\hline Produtos do fumo & 1,10 & 1,03 & 0,95 & 1,04 & 0,80 & 0,87 & 0,85 & 0,78 & 0,73 \\
\hline Preparação do couro & 0,30 & 0,28 & 0,23 & 0,25 & 0,22 & 0,31 & 0,36 & 0,33 & 0,34 \\
\hline Produtos de madeira & 1,11 & 1,13 & 1,10 & 1,39 & 1,20 & 1,26 & 1,41 & 1,68 & 1,69 \\
\hline \multicolumn{10}{|l|}{ Fabricação de papel e outras pastas para } \\
\hline fabricação de papel & 0,67 & 0,52 & 0,44 & 0,82 & 1,16 & 0,90 & 1,08 & 1,02 & 0,67 \\
\hline Fabricação de coque e refino de pertróleo & 5,45 & 4,48 & 5,60 & 9,20 & 13,27 & 11,93 & 12,16 & 14,321 & 13,50 \\
\hline Produção de álcool & 1,53 & 1,36 & 0,81 & 0,64 & 0,77 & 0,60 & 0,49 & 0,80 & 0,55 \\
\hline Metalurgia de não-ferrosos & 1,25 & 1,48 & 1,38 & 1,80 & 1,78 & 1,73 & 1,77 & 1,79 & 1,92 \\
\hline Cimento e outros produtos minerais não metálicos & 1,83 & 2,00 & 2,51 & 2,19 & 2,29 & 2,52 & 2,52 & 2,39 & 2,03 \\
\hline Intensiva em trabalho & 13,56 & 12,56 & 12,90 & 12,15 & 11,50 & 11,22 & 10,69 & 9,88 & 9,69 \\
\hline Têxteis & 3,26 & 2,86 & 2,93 & 3,06 & 2,84 & 2,54 & 2,45 & 2,21 & 2,17 \\
\hline Vestuário & 2,30 & 2,09 & 2,15 & 1,95 & 1,76 & 1,69 & 1,48 & 1,37 & 1,30 \\
\hline Artigos para viagem e artefatos de couro & 0,11 & 0,11 & 0,11 & 0,11 & 0,14 & 0,13 & 0,11 & 0,08 & 0,08 \\
\hline Calçados & 1,83 & 1,52 & 1,46 & 1,55 & 1,52 & 1,63 & 1,64 & 1,62 & 1,52 \\
\hline \multicolumn{10}{|l|}{ Fabricação de produtos de metal (exceto } \\
\hline máquinas e equipamentos) & 3,81 & 3,75 & 3,87 & 3,39 & 3,11 & 3,29 & 3,15 & 2,89 & 3,05 \\
\hline Móveis e indústrias dive & 2,25 & 2,23 & 2,38 & 2,09 & 2,13 & 1,94 & 1,86 & 1,71 & 1,57 \\
\hline Intensiva em escala & 35,78 & 36,91 & 35,79 & 33,80 & 33,19 & 31,69 & 32,64 & 33,153 & 35,61 \\
\hline \multicolumn{10}{|l|}{ Produtos cerâmicos para construção } \\
\hline civil e para usos diversos & 0,97 & 1,00 & 1,00 & 0,89 & 0,80 & 0,73 & 0,77 & 0,69 & 0,68 \\
\hline Fabricação de produtos e artefatos de papel e papelão & 3,07 & 2,90 & 3,07 & 3,20 & 3,13 & 2,95 & 3,43 & 3,31 & 3,18 \\
\hline Edição, impressão e reprodução de gravações & 4,92 & 5,25 & 5,25 & 4,18 & 4,08 & 3,69 & 3,22 & 2,92 & 2,92 \\
\hline Produtos químicos & 9,24 & 9,36 & 9,01 & 10,33 & 9,02 & 9,03 & 8,53 & 8,38 & 8,81 \\
\hline Artigos de b & 4,06 & 4,05 & 3,99 & 3,79 & 3,64 & 3,17 & 23 & 3,84 & 3,47 \\
\hline Vidro e produt & 0,61 & 0,65 & 0,55 & 0,60 & 0,59 & 0,58 & 0,60 & 0,56 & 0,60 \\
\hline Metalurgia básica & 4,15 & 4,34 & 4,21 & 4,21 & 4,58 & 4,44 & 5,22 & 5,34 & 7,40 \\
\hline Veículos automotores & 8,12 & 8,65 & 8,00 & 6,01 & 6,83 & 6,49 & 6,97 & 7,37 & 7,69 \\
\hline \multicolumn{10}{|l|}{ Equipamentos de transporte ferroviário, naval } \\
\hline e outros (exceto aeronáuticos) & 0,64 & 0,71 & 0,71 & 0,59 & 0,52 & 0,61 & 0,67 & 0,74 & 0,86 \\
\hline Diferenciada & 12,98 & 13,03 & 12,02 & 11,20 & 11,18 & 11,82 & 11,18 & $\mathbf{9 , 6 0} 1$ & 10,00 \\
\hline Máquinas e equipamentos & 6,81 & 6,94 & 6,40 & 5,75 & 5,28 & 5,92 & 6,07 & 5,71 & 5,82 \\
\hline Máquinas, aparelhos e materiais elétricos & 2,12 & 2,19 & 2,30 & 2,06 & 2,03 & 2,17 & 1,92 & 1,69 & 1,65 \\
\hline \multicolumn{10}{|l|}{ Material eletrônico, aparelhos e equipamentos } \\
\hline de comunicação & 3,55 & 3,39 & 2,78 & 2,88 & 3,36 & 3,28 & 2,73 & 1,75 & 2,12 \\
\hline Equipamentos de instrumentação médico-hospitalares & 0,29 & 0,29 & 0,31 & 0,30 & 0,30 & 0,25 & 0,29 & 0,28 & 0,27 \\
\hline Instumentos ópticos, cronômetros e relógios & 0,21 & 0,22 & 0,23 & 0,21 & 0,21 & 0,20 & 0,17 & 0,17 & 0,14 \\
\hline Baseada em ciência & 4,96 & 5,33 & 5,89 & 6,02 & 5,75 & 6,06 & 5,40 & 4,82 & 4,54 \\
\hline Produtos farmacêuticos & 3,42 & 3,49 & 3,68 & 3,64 & 2,88 & 2,54 & 2,62 & 2,45 & 2,32 \\
\hline Máquinas de escritório e equipamentos de informática & 0,49 & 0,54 & 0,56 & 0,76 & 1,11 & 1,34 & 0,72 & 0,60 & 0,47 \\
\hline Equipamentos de distribuição de energia elétrica & 0,51 & 0,63 & 0,85 & 0,41 & 0,39 & 0,42 & 0,35 & 0,54 & 0,40 \\
\hline Aparelhos e instrumentos de medida, teste e controle & 0,26 & 0,25 & 0,26 & 0,25 & 0,28 & 0,27 & 0,25 & 0,18 & 0,22 \\
\hline Máquinas e aparelhos de automação industrial & 0,08 & 0,08 & 0,09 & 0,08 & 0,08 & 0,07 & 0,08 & 0,06 & 0,06 \\
\hline Equipamentos de transporte aeronáuticos & 0,20 & 0,34 & 0,45 & 0,88 & 1,01 & 1,42 & 1,38 & 0,99 & 1,07 \\
\hline
\end{tabular}

Nota 1: Os totais podem ser ligeiramente superiores ou inferiores a 100\% por problemas de aproximação.

Fonte: Elaboração própria com base nos dados do IBGE, Pesquisa Industrial Anual. 
Tabela 2: Exportações industriais brasileiras por tipo de tecnologia

Taxas de crescimento médias anuais e participação setorial (em \%)

\begin{tabular}{|c|c|c|c|c|c|c|c|c|c|c|}
\hline \multirow[b]{2}{*}{ Setores industriais com tecnologia } & \multicolumn{5}{|c|}{$\begin{array}{l}\text { Taxas de crescimento } \\
\text { médias anuais (em \%) }\end{array}$} & \multicolumn{5}{|c|}{ Participação setorial (\%) } \\
\hline & $\begin{array}{l}1989- \\
1994\end{array}$ & $\begin{array}{r}1994- \\
1999\end{array}$ & $\begin{array}{l}1999- \\
2004\end{array}$ & $\begin{array}{l}2004 \\
-2005\end{array}$ & $\begin{array}{c}1989 \\
-2005\end{array}$ & 1989 & 1994 & 1999 & 2004 & 2005 \\
\hline Baseada em recursos naturais & 3,12 & 4,34 & 12,03 & 18,35 & 7,14 & 39,68 & 39,72 & 44,27 & 45,80 & 46,93 \\
\hline Extração de carvão mineral & $-13,66$ & $-5,56$ & $-1,62$ & 2,48 & $-6,51$ & 0,00 & 0,00 & 0,00 & 0,00 & 0,00 \\
\hline Extração de Petróleo, gás e serviços relacionados & & 505,42 & 326,89 & 53,59 & - & 0,00 & 0,00 & 0,00 & 2,94 & 3,91 \\
\hline Extração de minerais metálicos & $-1,09$ & 2,37 & 9,05 & 42,58 & 5,46 & 8,19 & 6,66 & 6,74 & 6,10 & 7,53 \\
\hline Extração de minerais não-metálicos & $-5,17$ & 9,50 & 10,97 & $-1,24$ & 4,45 & 0,61 & 0,40 & 0,57 & 0,56 & 0,48 \\
\hline Alimentos e bebidas & 3,04 & 5,57 & 10,49 & 10,08 & 6,55 & 17,44 & 17,39 & 20,55 & 19,84 & 18,91 \\
\hline Produtos do fumo & 35,96 & $-13,87$ & 1,66 & $-1,09$ & 5,53 & 0,29 & 1,15 & 0,49 & 0,31 & 0,27 \\
\hline Preparação do couro & 12,05 & 4,56 & 12,95 & 0,85 & 9,21 & 0,81 & 1,23 & 1,38 & 1,49 & 1,30 \\
\hline Produtos de madeira & 18,96 & 4,70 & 13,76 & $-7,00$ & 11,00 & 1,37 & 2,80 & 3,17 & 3,54 & 2,85 \\
\hline Fabricação de papel e outras pastas para fabricação de papel & 2,89 & 7,00 & 3,45 & 10,09 & 4,78 & 2,31 & 2,28 & 2,89 & 2,00 & 1,91 \\
\hline Fabricação de coque e refino de pertróleo & $-3,06$ & 7,10 & 19,28 & 42,68 & 9,31 & 2,85 & 2,10 & 2,66 & 3,77 & 4,65 \\
\hline Produção de álcool & 33,76 & $-6,19$ & 44,90 & 43,15 & 23,27 & 0,06 & 0,24 & 0,16 & 0,58 & 0,72 \\
\hline Metalurgia de não-ferrosos & 0,80 & 2,35 & 5,95 & 6,48 & 3,22 & 5,44 & 4,86 & 4,92 & 3,85 & 3,55 \\
\hline Cimento e outros produtos minerais não metálicos & 17,86 & 5,81 & 13,33 & 20,39 & 12,72 & 0,32 & 0,62 & 0,74 & 0,81 & 0,85 \\
\hline Intensiva em trabalho & 4,31 & $-3,69$ & 8,49 & 0,74 & 2,77 & 10,42 & 11,05 & 8,25 & 7,26 & 6,34 \\
\hline Têxteis & 0,22 & $-5,31$ & 10,08 & $-1,15$ & 1,30 & 3,07 & 2,66 & 1,83 & 1,73 & 1,48 \\
\hline Vestuário & 4,40 & $-15,95$ & 12,40 & $-5,65$ & $-0,79$ & 0,94 & 1,00 & 0,38 & 0,40 & 0,32 \\
\hline Artigos para viagem e artefatos de couro & 2,24 & 14,47 & 17,06 & $-2,39$ & 10,17 & 0,06 & 0,06 & 0,11 & 0,14 & 0,12 \\
\hline Calçados & 2,89 & $-4,52$ & 3,89 & $-2,83$ & 0,46 & 4,40 & 4,36 & 3,12 & 2,21 & 1,86 \\
\hline \multicolumn{11}{|l|}{ Fabricação de produtos de metal (exceto máquinas } \\
\hline e equipamentos) & 9,03 & $-2,60$ & 9,00 & 16,82 & 5,70 & 1,17 & 1,55 & 1,22 & 1,10 & 1,12 \\
\hline Móveis e indústrias diversas & 16,26 & 4,57 & 12,48 & $-1,38$ & 10,18 & 0,78 & 1,42 & 1,60 & 1,69 & 1,44 \\
\hline Intensiva em escala & 2,49 & $-1,04$ & 12,09 & 14,72 & 4,99 & 36,04 & 34,98 & 29,92 & 31,03 & 30,82 \\
\hline Produtos cerâmicos para construçâo civil e para usos diversos & 5,68 & $-0,75$ & 10,28 & 3,09 & 4,85 & 0,62 & 0,70 & 0,61 & 0,58 & 0,52 \\
\hline Fabricação de produtos e artefatos de papel e papelāo & 7,62 & $-1,68$ & 1,81 & 9,60 & 2,94 & 2,02 & 2,50 & 2,07 & 1,33 & 1,26 \\
\hline Edição, impressão e reprodução de gravaçōes & 17,15 & 3,73 & 7,95 & $-11,50$ & 8,02 & 0,07 & 0,14 & 0,15 & 0,13 & 0,10 \\
\hline Produtos químicos & 3,53 & 2,08 & 8,18 & 14,31 & 5,15 & 6,59 & 6,72 & 6,71 & 5,83 & 5,77 \\
\hline Artigos de borracha e plástico & 12,66 & 0,61 & 6,45 & 12,64 & 6,84 & 1,40 & 2,18 & 2,02 & 1,62 & 1,58 \\
\hline Vidro e produtos de vidro & 11,49 & 6,71 & 5,38 & $-3,16$ & 7,10 & 0,23 & 0,35 & 0,43 & 0,33 & 0,28 \\
\hline Metalurgia básica & $-2,73$ & $-6,11$ & 14,24 & 19,04 & 2,44 & 14,80 & 11,06 & 7,27 & 8,30 & 8,55 \\
\hline Veículos automotores & 3,31 & 2,87 & 12,67 & 25,61 & 7,31 & 9,98 & 10,09 & 10,47 & 11,14 & 12,12 \\
\hline \multicolumn{11}{|l|}{ Equipamentos de transporte ferroviário, naval } \\
\hline outros (exceto aeronáuticos) & 34,67 & $-31,15$ & 76,99 & $-57,81$ & 10,61 & 0,33 & 1,25 & 0,17 & 1,77 & 0,65 \\
\hline Diferenciada & 5,26 & 0,70 & 11,54 & 21,23 & 6,65 & 10,06 & 11,15 & 10,41 & 10,53 & 11,05 \\
\hline Máquinas e equipamentos & 6,56 & $-1,67$ & 12,36 & 3,18 & 5,44 & 6,61 & 7,80 & 6,46 & 6,78 & 6,06 \\
\hline Máquinas, aparelhos e materiais elétricos & 11,61 & $-0,13$ & 10,34 & 31,16 & 8,51 & 1,11 & 1,64 & 1,47 & 1,41 & 1,60 \\
\hline \multicolumn{11}{|l|}{ Material eletrônico, aparelhos e equipamentos } \\
\hline de comunicação & $-2,77$ & 10,29 & 10,35 & 73,51 & 9,10 & 2,00 & 1,49 & 2,19 & 2,10 & 3,16 \\
\hline Equipamentos de instrumentação médico-hospitalares & 15,88 & 9,00 & 12,53 & 14,51 & 12,56 & 0,07 & 0,13 & 0,18 & 0,19 & 0,19 \\
\hline Instumentos ópticos, cronômetros e relógios & $-17,88$ & 5,37 & $-5,84$ & 16,37 & $-5,31$ & 0,27 & 0,09 & 0,10 & 0,04 & 0,04 \\
\hline Baseada em ciência & $-1,05$ & 20,72 & 5,10 & 4,37 & 7,66 & 3,80 & 3,10 & 7,16 & 5,38 & 4,86 \\
\hline Produtos farmacêuticos & 11,45 & 15,36 & 1,20 & 20,20 & 9,83 & 0,28 & 0,41 & 0,75 & 0,47 & 0,49 \\
\hline Máquinas de escritório e equipamentos de informática & $-3,31$ & 15,57 & $-9,56$ & 33,52 & 2,16 & 0,81 & 0,59 & 1,09 & 0,39 & 0,45 \\
\hline Equipamentos de distribuição de energia elétrica & 11,10 & 0,05 & 5,14 & 8,26 & 5,51 & 0,22 & 0,32 & 0,29 & 0,22 & 0,20 \\
\hline Aparelhos e instrumentos de medida, teste e controle & 15,42 & 4,48 & $-1,16$ & 10,53 & 6,30 & 0,24 & 0,42 & 0,47 & 0,26 & 0,25 \\
\hline Máquinas e aparelhos de automação industrial & - & - & - & - & - & 0,00 & 0,00 & 0,00 & 0,00 & 0,00 \\
\hline Equipamentos de transporte aeronáuticos & $-6,78$ & 29,95 & 8,69 & $-0,85$ & 8,92 & 2,26 & 1,36 & 4,55 & 4,05 & 3,48 \\
\hline Total da Indústria & 3,10 & 2,10 & 11,28 & 15,49 & 6,02 & 86,69 & 85,57 & 89,72 & 89,05 & 89,97 \\
\hline
\end{tabular}

Nota: 1. Para o cálculo das taxas de crescimento médias anuais, o valor das exportaçōes foi deflacionado com base no Producer Price IndexWholesale (PPI - Wholesale) - dos E.U.A, a preços de 1994

2. O total não corresponde a $100 \%$, porque os dados restringem-se à indústria (incluíndo a extrativa mineral)

Fonte: Elaboração própria com base nos dados da SECEX. 
dias anuais de crescimento bastante expressivas das vendas externas de produtos industrializados brasileiros resultaram da combinação de fatores internos e externos, como a tendência de desvalorização do Real (entre 1999 e 2003), das elevadas taxas de crescimento da economia mundial (após 2003) e do forte aumento do preço internacional de diversas commodities exportadas pelo País (principalmente nos anos de 2004 e 2005).

As alterações observadas nas participações das exportações de cada setor no total das vendas externas de produtos industrializados confirmam uma tênue mudança do padrão de especialização internacional. De fato, enquanto o conjunto dos setores com tecnologias baseadas em recursos naturais e intensivas em trabalho representavam 50\% do total exportado em 1989, essa participação avançou para 53,3\% em 2005. Em contrapartida, a participação conjunta dos três últimos grupos por categorias tecnológicas reduziu-se de $49,9 \%$ para $46,7 \%$ em igual período.

Entretanto, é prematuro identificar tais mudanças como sintomas de desindustrialização no Brasil, porque no período 1989-2005: i) os setores com tecnologias diferenciadas e baseadas em ciência, aumentaram, ainda que marginalmente, suas participações de $10,1 \%$ para $11,1 \%$, e de $3,8 \%$ para $4,9 \%$, respectivamente; ii) no grupo de setores com tecnologias baseadas em recursos naturais, constata-se que o avanço da participação das vendas externas do segmento de extração de petróleo e gás (para quase $4 \%$ do total de bens industrializados) resultou de um efeito estatístico no crescimento das exportações de um produto que, até 1999 , teve presença praticamente nula na pauta.

Em suma, até aqui não se pode concluir que o Brasil tenha passado por desindustrialização, porque não se assistiu a um processo generalizado de mudança na realocação dos recursos produtivos e no padrão de especialização dos setores com tecnologias intensivas em escala, diferenciada e science-based para as indústrias tecnologicamente baseadas em recursos naturais e em trabalho.

A fim de aprofundarmos a análise das mudanças ocorridas no padrão de especialização, utilizamos uma tipologia alternativa proposta por Lall (2000), em que os setores produtivos da economia (incluindo também a agropecuária) são divididos segundo o grau de sofisticação tecnológica: assim, enquanto os setores primários e/ou manufaturados intensivos em recursos naturais e de baixa tecnologia possuem, salvo as exceções de praxe, menor grau de agregação de valor e utilizam técnicas produtivas tradicionais, as indústrias de média e alta tecnologia despendem elevados gastos em P \& D, incorporam maior nível de conhecimento e contam com grande potencial de difusão de externalidades tecnológicas (spillovers) para os demais setores da economia. Para que se configure um processo generalizado de desindustrialização, é preciso constatar um aumento significativo da participação das exportações do primeiro grupo de setores em relação ao total exportado brasileiro em detrimento do segundo.

A tabela 3 apresenta a evolução das exportações totais segundo a referida classificação. Os dados confirmam o medíocre desempenho das exportações no decênio 1989-1999, sobretudo entre os anos 1994 e 1999, e a sustentação de taxas expressivas de crescimento das vendas externas a partir do ajustamento cambial, em 1999. Os resultados mostram também que a valorização do Real em re- 
lação ao Dólar em 2005 não afetou adversamente o desempenho das exportações de bens manufaturados, que cresceram $12,5 \%$ em relação ao ano anterior, com destaque para o segmento de manufaturados de alta tecnologia.

Tabela 3 Exportações: brasileiras segundo a intensidade tecnológica no período 1989-2005

Taxas de crescimento médias anuais e composição setorial (em \%)

Taxas de crescimento
médias anuais (em \%)

Participação setorial (\%)

\begin{tabular}{l|rrrrl|rrrrr}
\multicolumn{10}{c}{ médias anuais (em \%) } \\
\hline $\begin{array}{l}\text { Setores produtivos por } \\
\text { intensidade tenológica }\end{array}$ & $\mathbf{1 9 8 9 -}$ & $\mathbf{1 9 9 4 -}$ & $\mathbf{1 9 9 9 -}$ & $\mathbf{2 0 0 4}$ & $\mathbf{1 9 8 9}$ & $\mathbf{1 9 8 9}$ & $\mathbf{1 9 9 4}$ & $\mathbf{1 9 9 9}$ & $\mathbf{2 0 0 4}$ & $\mathbf{2 0 0 5}$ \\
\hline Produtos primários & $\mathbf{1 9 9 4}$ & $\mathbf{1 9 9 9}$ & $\mathbf{2 0 0 4}$ & $\mathbf{- 2 0 0 5}$ & $\mathbf{- 2 0 0 5}$ & & & & & \\
Produtos manufaturados & 2,66 & 1,68 & 16,43 & 9,44 & 6,88 & 11,14 & 10,77 & 11,06 & 13,76 & 13,17 \\
Baseados em recursos naturais & 2,75 & 0,84 & 10,57 & 12,47 & 4,34 & 87,90 & 88,08 & 88,74 & 85,32 & 85,32 \\
Baixa tecnologia & 4,50 & 1,97 & 10,56 & 17,03 & 6,30 & 32,79 & 34,62 & 36,06 & 34,66 & 35,48 \\
Média tecnologia & 1,20 & $-2,64$ & 9,73 & 8,68 & 3,00 & 28,05 & 25,22 & 20,85 & 19,29 & 18,34 \\
Alta tecnologia & 5,32 & 0,36 & 12,65 & 11,59 & 6,33 & 21,61 & 23,72 & 22,82 & 24,07 & 23,50 \\
Outras transações & $-0,42$ & 16,12 & 6,81 & 25,37 & 8,34 & 5,45 & 4,52 & 9,02 & 7,29 & 8,00 \\
Total exportado & 17,15 & 3,73 & 7,95 & $-11,50$ & 8,02 & 0,96 & 1,15 & 0,20 & 0,92 & 1,50 \\
\hline & 3,37 & 1,14 & 11,44 & 14,31 & 5,77 & 100,00 & 100,00 & 100,00 & 100,00 & 100,00 \\
\hline
\end{tabular}

Notas: 1. Para o cálculo das taxas de crescimento médias anuais, o valor das exportações foi deflacionado com base no Producer Price Indes - Wholesale (PPI - Wholesale) - dos E.U.A, a preços de 1994

2. Grosso modo, os segmentos integrantes de cada setor são assim resumidos por Lall (2003): primários: agropecuária e extração dt petróleo, carvão e gás; manufaturados baseados em recursos naturais: alimentos e carnes preparadas, bebidas, madeira, derivados d $\epsilon$ petróleo e borracha, cimento e vidro; manufaturados de baixa tecnologia: têxteis, vestuário \& calçados, móveis, produtos de plásticos estruturas simples de metal, jóias, brinquedos, produtos de couro e porcelana; manufaturados de média tecnologia: veículos automotores partes e peças, fibras sintéticas, produtos químicos, fertilizantes, aço, estruturas elaboradas de metal, máquinas industriais, bombas 8 motores elétricos, navios e relógios; manufaturados de alta tecnologia: máquinas \& equipamentos de escritório, de processamentos de dados e de telecomunicações, turbinas, geradores, produtos farmacêuticos, produtos aeronáuticos \& aeroespaciais, instrumentos ópticos $\epsilon$ de precisão; outras transações: material de impressão, material cinematográfico, ouro e produtos diversos. A elaboração final foi feita con base na classificação original e bem mais detalhada que se encontra no Apêndice de Lall (2000).

No que se refere ao padrão de especialização internacional, as alterações nas participações das vendas externas de produtos primários e manufaturados em relação ao total das exportações foram pouco expressivas (avanço na participação do primeiro grupo em 2 pontos percentuais e queda do segundo em três pontos percentuais). As vendas externas de manufaturados representavam $85 \%$ do total das exportações brasileiras em 2005 (contra 88\% em 1989). Note ainda que, não obstante os impactos imediatos da liberalização comercial e da sobrevalorização do Real durante o período 1994-1998, a participação de produtos primários e de manufaturados na pauta exportada brasileira manteve-se praticamente inalterada entre 1989 e 1999 (em torno de $11 \%$ e $88 \%$, respectivamente).

Além disso, a análise das mudanças ocorridas na estrutura interna das exportações de bens manufaturados nos período 1989-2005 permite descartar a hipótese de que o Brasil teria retrocedido a um padrão de especialização "ricardiano rico em recursos", já que: i) a participação conjunta das vendas externas de produtos primários, manufaturados intensivos em recursos naturais e manufaturados de baixa tecnologia teve um decréscimo de $72 \%$ para $67 \%$; ii) o aumento da participação das exportações de manufaturados intensivos em recursos naturais foi pouco significativo (de apenas 2 pontos percentuais) para configurar "desindustrialização" consoante com a "nova doença holandesa"; iii) com a perda expressiva do peso relativo das exportações de manufaturados de baixa tecnologia (de $28 \%$ para $18 \%$ ), a participação conjunta deste grupo e do de manufaturados intensivos em 
recursos naturais recuou de $61 \%$ para $53 \%$ em igual período; iv) tanto o grupo de manufaturados de média como o de alta tecnologia conseguiu ampliar, ainda que não expressivamente, suas respectivas participações no total exportado (de $22 \%$ para $24 \%$, e de $5 \%$ para $8 \%$ ); e, v) com isso, a soma das participações das vendas externas destes dois grupos no total das exportações brasileiras teve um acréscimo de 5 pontos percentuais (de $27 \%$ para $32 \%$ ) em igual período.

Por outro lado, a despeito de não se ter manifestado até agora um processo de desindustrialização, sobretudo porque as evidências não confirmam um retorno a um padrão generalizado de especialização exportadora baseada em produtos primários e/ou intensivos em recursos naturais, devem ser ressalvadas duas evidências preocupantes. A primeira diz respeito à perda muito expressiva do peso relativo dos produtos industrializados intensivos em trabalho no total do valor adicionado e das exportações brasileiras. Essa perda não seria tão preocupante caso tivesse sido compensada, pelo menos de forma significativa, pelo avanço dos setores com tecnologias intensivas em escala, diferenciadas ou baseadas em ciências, os quais têm enorme potencial para disseminar externalidades tecnológicas para o restante da economia. Afinal, ainda que nos setores intensivos em trabalho predominem tecnologias tradicionais, eles, pelo menos, detêm elevada capacidade para absorver trabalhadores de menor qualificação, os quais, no Brasil, costumam estar, sobretudo nas fases de menor crescimento econômico, desempregados ou na informalidade.

A segunda está relacionada à tendência recorrente de sobrevalorização real da moeda brasileira em relação ao dólar. O gráfico 5 mostra os índices das taxas de câmbio reais efetivas R $\$ / U S \$$, ponderados pela participação dos 16 principais parceiros comerciais na pauta de exportações brasileira. Nota-se que a tendência de sobrevalorização do Real tem sido recorrente desde o final da década de 1980, só tendo sido interrompida entre o início de 1999 (com o ataque especulativo que levou ao regime de flutuação cambial) e o final de $2003 .{ }^{22}$ Como sugere a literatura teórica e empírica sobre regimes cambiais, os prováveis benefícios de curto prazo decorrentes da apreciação das moedas nacionais por períodos prolongados de tempo - como a possibilidade de barateamento de importações de máquinas e equipamentos, redução das pressões inflacionárias, entre os poucos não compensam os enormes custos micro e macroeconômicos no longo prazo, principalmente a desestruturação do setor exportador de manufaturados e a vulnerabilidade a ataques especulativos e a crises do balanço de pagamentos. ${ }^{23}{ }^{24}$

\footnotetext{
${ }^{22}$ Mesmo durante a fase de inflação crônica (no gráfico, entre 1989 e meados de 1994), a indexação generalizada (inclusive com correções da taxa de câmbio nominal pelo Banco Central do Brasil) não foi suficiente para manter a paridade real da moeda brasileira relativamente às moedas de seus principais parceiros comerciais. Por outro lado, entre janeiro de 1999 e o final de 2003, a apreciação real da moeda brasileira só ocorreu em fases episódicas (de junho a novembro de 2000; e de março a abril de 2002), sem ter alterado, porém, a tendência de depreciação.

${ }^{23}$ Para uma discussão teórica, ver Helmers (1988), Dornbusch (1988), Bruno (1991) e Obstfeld e Rogoff (1996). Para as evidências empíricas, ver Dornbusch e Werner (1994) e Goldfajn e Valdés (1996).

${ }^{24} \mathrm{~A}$ apreciação real da moeda de um país em relação a seus parceiros só não configura uma situação de vulnerabilidade macroeconômica no longo prazo se ela refletir as elevadas taxas de crescimento da
} 
Gráfico 5: Índices de taxas de câmbio reais efetivas Média de $2000=100$

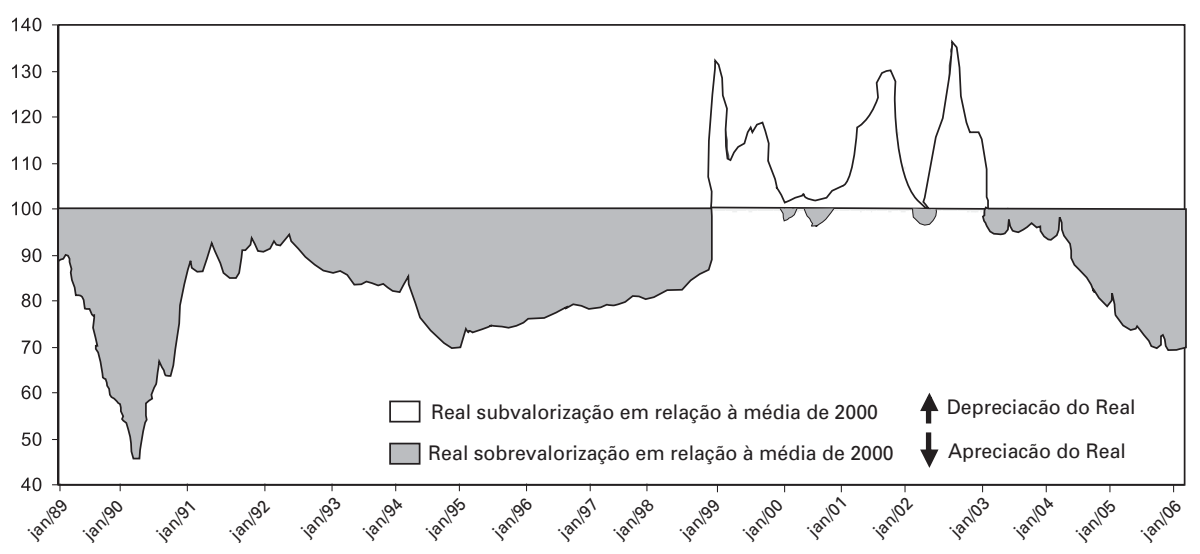

Nota: Taxas de câmbio R\$/US\$, deflacionadas pelos Índices de Preços por Atacado-Oferta Global (IPA-OG) da indústria de transformação brasileira e pelos Índices de Preços por Atacado (IPA) dos bens industrializados dos 16 principais parceiros comerciais do Brasil, ponderadas pela participação de cada parceiro na pauta de exportações brasileira de manufaturados de 2001.

Fonte: Elaboração própria, com base nos dados do IPEADATA.

Como lembraram Castro e Souza (2006) em artigo recente, o episódio de sobrevalorização do Real entre 1994 e 1998 pelo menos consolidou a modernização da indústria brasileira mediante a absorção de novas técnicas produtivas e/ou incorporação de equipamentos importados, permitindo, com isso, um expressivo aumento da produtividade e um "relativo emparelhamento no que se refere a processos produtivos". ${ }^{25}$ No quadro atual de apreciação do Real, "tudo leva a crer que a resposta das empresas não mais tenderá a ser buscada por meio da (rápida) absorção de técnicas maduras”. Como agravante, tendo em conta que, no período 1999-2004, a indústria brasileira mostrou taxas anuais de variação negativas da produtividade do trabalho, pode-se suspeitar que, mantida a sobrevalorização da moeda brasileira em termos reais como tendência de longo prazo, potencializam-se, de fato, os riscos de desindustrialização no Brasil. Esses riscos

produtividade em seus setores tradables, consoante o efeito Harrod-Balassa-Samuelson. Como lembram Obstfeld e Rogoff (1996, p.212), "os países só se tornam ricos por meio de elevadas taxas de incremento da produtividade dos bens tradables (...) e a mais notável predição da proposição de Harrod-Balassa-Samuelson é que os níveis de preços tendem a aumentar nos países de maior renda per capita" (relativamente aos níveis de preços dos demais parceiros, expressos numa mesma moeda).

${ }^{25}$ A propósito, é importante ressaltar que existem evidências empíricas que corroboram essa conclusão. Em estudo inédito, Nassif (2006) constrói uma regressão que permite analisar os ganhos de produtividade observados no Brasil entre 1988 e 1998, utilizando como variáveis de controle não apenas as associadas à liberalização comercial, como também as relacionadas à mudança do ambiente macroeconômico. As variáveis que mostraram maior nível de significância para explicar os ganhos de eficiência no período foram a sobrevalorização da moeda brasileira em relação ao dólar em termos reais e a drástica queda das taxas de inflação no Brasil. Para mais detalhes, ver Nassif (2006). 
podem ser majorados pela "nova industrialização" da China, que seguirá produzindo mudanças profundas na divisão internacional do trabalho. ${ }^{26}$

\section{CONCLUSÕES}

Este artigo procurou investigar se o Brasil sofreu algum processo de desindustrialização, seja pela via "natural", que costuma atingir um país quando este transita para estágios mais avançados de desenvolvimento econômico, seja pelo contágio precoce de uma "nova doença holandesa", que acarreta o retorno a um padrão de especialização produtiva e exportadora baseado em produtos intensivos em recursos naturais.

$\mathrm{Na}$ verdade, a forte perda de participação da indústria no PIB brasileiro foi, pelo menos enquanto tendência de longo prazo, um fenômeno circunscrito basicamente à segunda metade dos anos oitenta; e se iniciou antes da implementação das reformas econômicas estruturais, notadamente da liberalização comercial. Essa queda de participação ocorreu no bojo de uma forte retração da produtividade do trabalho, de um cenário de estagnação econômica e de elevadas taxas de inflação.

Em termos gerais, o que se observou na segunda metade dos anos 1980 foi uma queda da participação da indústria no PIB, em meio a uma fortíssima retração na produtividade do trabalho e a um cenário de estagnação econômica. Entre 1991 e 1998, o cenário foi de manutenção do peso da indústria, com aumento na produtividade do trabalho, mas queda nas taxas de formação bruta de capital. Após 1999, houve retração da produtividade e manutenção das baixas taxas de investimento. Ou seja, o comportamento instável da produtividade e os níveis reduzidos de investimento, desde o início dos anos 1990, contribuíram para impedir o retorno da participação da indústria no PIB aos níveis médios anuais prevalecentes na década de 1980.

Portanto, o período de 1990 até o presente não pode ser qualificado como de "desindustrialização". Apesar das baixas taxas de crescimento médias anuais do PIB brasileiro entre 1990 e 2000, a indústria de transformação doméstica conseguiu manter um nível de participação médio anual da ordem de $22 \%$ no período, praticamente o mesmo percentual observado em 1990. Nos últimos anos, houve um ligeiro aumento dessa participação, chegando a 23\% em 2004.

As evidências empíricas também não confirmam uma "nova doença holandesa" no Brasil, seja porque não se verificou uma realocação generalizada de fatores produtivos para os segmentos que constituem o grupo de indústrias com tecnologias baseadas em recursos naturais, seja porque não se configurou um re-

\footnotetext{
${ }^{26}$ Este último comentário foi sugerido por Júlio Sérgio Gomes de Almeida, a quem o autor agradece pela leitura de versão preliminar deste artigo.
} 
torno vigoroso a um padrão de especialização exportadora em produtos intensivos em recursos naturais ou em trabalho. Prova disso é que a participação conjunta dos produtos primários, dos manufaturados intensivos em recursos naturais e dos manufaturados de baixa tecnologia sofreu um decréscimo de $72 \%$ para $67 \%$ entre 1989 e 2005.

De todo modo, o artigo alerta para os riscos no longo prazo inerentes à tendência recorrente de sobrevalorização da moeda brasileira em relação ao dólar em termos reais, fato observado desde o final da década de 1980 até o presente (abril de 2006) - com exceção do período 1999-2003. Esses riscos estão associados não apenas à perda de competitividade industrial, como principalmente à deflagração de um processo precoce de desindustrialização no Brasil, o qual, se bem não tenha passado de mera conjectura até o momento, poderia, sim, em perspectiva de longo prazo, se transformar num fenômeno real.

\section{REFERÊNCIAS BIBLIOGRÁFICAS}

Barros, Luis Carlos M. (2006) "Uma encruzilhada para o Brasil”. Folha de S. Paulo, 3/02

Bonelli, Regis (2005) "Industrialização e desenvolvimento. Notas e conjecturas com foco na experiência do Brasil”. Texto preparado para o seminário Industrialização, Desindustrialização e Desenvolvimento, organizado pelo IEDI e FIESP. Mimeo.

Bonelli, Regis e Fonseca, Renato (1998) "Ganhos de produtividade e de eficiência: novos resultados para a economia brasileira”. Pesquisa e Planejamento Econômico 28(2): 273-314.

Bresser-Pereira, Luis Carlos (2005) "Maldição dos recursos naturais”. Folha de S. Paulo, 6/06.

Bruno, Michael (1978) "Duality, intermediate inputs and value-added". In: Fuss, M. e McFadden, D.L. (ed.). Production Economics: a Dual Approach to Theory and Applications, V. 2 (Applications of the Theory of Production). Amsterdã: North Holland.

. (1991). "High inflation and the nominal anchors of an open economy". Essays in International Finance 183. Nova Jersey: Princeton University, junho.

Brynjolfsson, Eric e Hitt, Lorin M. (2003) “Computing productivity: firm-level evidence”. MIT Sloan Working Paper 4.210-4.301, junho.

Carvalho, Paulo G. M. (2000) As Causas do Aumento da Produtividade da Indústria Brasileira nos anos 90. Tese de Doutoramento em Economia. Rio de Janeiro: Instituto de Economia, Universidade Federal do Rio de Janeiro.

Castro, Antônio B. e Souza, Francisco E. P. (2006) “Dois episódios de valorização cambial”. Folha de S. Paulo, 29/03/.

Clark, Colin (1957) The Conditions of Economic Progress. London: Macmillan.

Corden, W. Max e Neary, J. Peter (1982) "Booming sector and de-industrialization in a small open economy”. Economic Journal 92: 825-848.

Dornbusch, Rudiger (1988) "Overvaluation and trade balance". In: Dornbusch, R. e Helmers, F. Leslie C.H. (ed.) The Open Economy: Tools for Policymakers in Developing Countries. Washington, DC/Oxford: The World Bank/ Oxford University Press.

Dornbusch, Rudiger e Werner, Alejandro (1994) “Mexico: stabilization, reform, and no growth". Brookings Papers on Economic Activity 1. Washington, DC: The Brookings Institution.

Feijó, Carmem A., Carvalho, Paulo G. M. e Almeida, Júlio S. G. (2005) “Ocorreu uma desindustrialização no Brasil?”. São Paulo: IEDI, novembro, mimeo.

Goldfajn, Ilan e Valdés, Rodrigo O. (1996) "The aftermath of appreciations". NBER Working Paper Series 5650. Cambridge, MA: National Bureau of Economic Research. 
Gonçalves, Reinaldo (2000) O Brasil e o Comércio Internacional. Transformações e Perspectivas. São Paulo: Contexto.

. (2005) Economia Política Internacional. Rio de Janeiro: Campus.

Guimarães, Eduardo A. (1995) "Taxas de câmbio setoriais: metodologia e resultados". Texto para Discussão 106. Rio de Janeiro: Fundação Centro de Estudos do Comércio Exterior (FUNCEX), abril.

Hay, Donald A. (2001). "The post-1990 brazilian trade liberalization and the performance of large manufacturing firms: productivity, market share and profits". The Economic Journal 111(473): 620-641.

Helmers, F. Leslie C. H. (1988) “The real exchange rate” In: Dornbusch, R. e Helmers, F. Leslie C. H (ed.) The Open Economy: Tools for Policymakers in Developing Countries. Washington, DC/Oxford: The World Bank/Oxford University Press.

IEDI (2005). "Expansão da produtividade no $1^{\circ}$ semestre". Carta IEDI 173. São Paulo: Instituto de Estudos para o Desenvolvimento Industrial.

Jones, Ronald W. e Neary, J. Peter (1984) "The positive theory of international trade". In: Handbook of International Economics vol. 1. Amsterdã: Elsevier.

Jorgenson, D.W., Ho, M.S. e Stiroh, K. J. (2002) "Information technology, education, and the sources of economic growth across industries". Março, mimeo.

Lall, Sanjaya (2000a) "Technological change and industrialization in the Asian newly industrializing economies: achievements and challenges". In: Kim, Linsu e Nelson, Richard. Technology, Learning, and Innovation. Experiences of Newly Industrializing Economies. Cambridge: Cambridge University Press.

. (2000b) "The technological structure and performance of developing countries manufactured exports, 1985-1998”. Oxford Development Studies 28(3): 337-369.

. (2003) "Foreign direct investment, technology development and competitiveness: issues and evidence". In: Lall, Sanjaya e Urata, Shujiro, Competitiveness, FDI and Technological Activity in East Asia. Cheltenham (UK): Edward Elgar.

McKinsey Global Institute (2001) U.S. Productivity Growth 1995-2000. Understanding the Contribution of Information Technology Relative to Other Factors. Washington DC: McKinsey \& Co.

Moreira, Mauricio M. e Correa, Paulo G. (1996) "Abertura comercial e indústria: o que se pode esperar e o que se vem obtendo". Texto para Discussão 49. Rio de Janeiro: BNDES.

Muendler, M. (2004) "Trade, technology, and productivity: a study of Brazilian manufacturers, 19861998". CESifo Working Paper, 1148, março.

Nakahodo, Sidney N. e Jank, Marcos S. (2006) “A falácia da doença holandesa”. Documento de Pesquisa. São Paulo: Instituto de Estudos do Comércio e Negociações Internacionais. Mimeo.

Nassif, André (2005). "As fontes de mudança da eficiência técnica da indústria brasileira após a liberalização comercial: uma estimação econométrica por dados de plantas”. Economia Aplicada 9(1), abril-junho.

. (2006) "Measuring the sources of labour productivity change in the Brazilian manufacturing plants: the role of trade liberalization and the macroeconomic environment". Trabalho apresentado no 2006 Latin American Meeting of the Econometric Society (LAMES) and Latin American and Caribbean Economic Association (LACEA). Instituto Tecnológico Autónomo de México (ITAM), México DF, 2 a 4 de novembro de 2006. Disponível em: http://www.laceala mes2006.itam.mx/.

Obstfeld, Maurice e Rogoff, Kenneth (1996) Foundations of International Macroeconomics. Cambridge, MA: The MIT Press.

OECD (1987) Structural Adjustment and Economic Performance. Paris: Organization for Economic Cooperation and Development.

Palma, J. Gabriel (2005) "Four sources of deindustrialization and a new concept of the Dutch disease". In: Ocampo, J.A. (ed.) Beyond Reforms. Palo Alto (CA): Stanford University Press. 
Pavitt, Keith (1984) "Sectoral patterns of technical change: towards a taxonomy and a Theory". Research Policy 13: 343-373.

Reinert, Erik S. (1999) "The role of the State in economic growth". Journal of Economic Studies 26(4/5): 268-326.

Rowthorn, Robert (1994) “Korea at the cross-roads”. Working Paper 11, ESRC. Cambridge: Centre for Business Research, Cambridge University.

Rowthorn, Robert e Ramaswamy, Ramana (1999) “Growth, trade, and deindustrialization”. IMF Staff Papers 46(1). Washington, DC: International Monetary Fund.

Rowthorn, Robert e Wells, John R. (1987) De-industrialization and Foreign Trade. Cambridge: Cambridge University Press.

Salm, Cláudio, Sabóia, João e Carvalho, Paulo G. (1997) "Produtividade na indústria brasileira: questões metodológicas e novas evidências empíricas”. Pesquisa e Planejamento Econômico 27(2): 377-396'. Rio de Janeiro: IPEA.

Van Ark, Bart, Inklaar, Robert e McGuckin, Robert H. (2003) "ICT and productivity in Europe and the United States. where do the differences come from?”. CESifo Economic Studies 49(3): 295318. 